\title{
Pengembangan Website Radio SSFM Semarang dengan Codeigniter Berbasis Model View Controller
}

\author{
Ahmad Salafuddin ${ }^{1}$, De Rosal Ignatius Moses Setiadi², Desi Purwanti Kusumaningrum ${ }^{3}$, Eko Hari \\ Rachmawanto ${ }^{4}$, Christy Atika Sari ${ }^{5}$ \\ Prodi Teknik Informatika, S1 Fakultas Ilmu Komputer, Universitas Dian Nuswantoro Semarang \\ Jl. Imam Bonjol No.207, Pendrikan Kidul, Semarang. Telp. 024-3517261 \\ e-mail: ${ }^{1}$ xporar@gmail.com, ${ }^{2}$ moses@dsn.dinus.ac.id, ${ }^{3}$ desi.purwanti@dsn.dinus.ac.id, \\ 4eko.hari@dsn.dinus.ac.id, ${ }^{5}$ atika.sari@dsn.dinus.ac.id
}

\begin{abstract}
Abstrak
Radio SSFM Semarang merupakan salah satu radio yang pernah populer di Semarang. Radio ini merupakan salah satu anak perusahaan Suara Merdeka grup. Radio SSFM Semarang perlu dikembangkan kembali agar dapat bersaing dengan radio lain. Salah satu yang perlu dikembangkan adalah website radio SSFM. Website ini sebelumnya hanya digunakan untuk melakukan streaming dan dibuat dengan PHP biasa yang belum menggunakan framework sehingga akan sulit dilakukan maintenance. Penelitian ini melakukan perancangan ulang untuk membuat perubahan yang signifikan pada website, sehingga penyiaran juga dapat dilakukan dengan sistem berbasis web yang modern, kreatif dan inovatif. Framework codeigniter dan metode Model View Controller (MVC) diusulkan untuk mengimplementasikan website SSFM Semarang. Penggunaan framework codeigniter dan metode MVC diusulkan agar website dapat lebih mudah dipelihara, cepat, andal dan mudah diakses. Website yang telah dibangun telah diuji dengan metode blackbox dan uji performa dengan pengukuran waktu load website. Hasil pengujian menunjukkan bahwa penggunaan metode MVC dapat meningkatkan performa kecepatan load website. Dengan hasil pengembangan website ini diharapkan developer tidak perlu banyak dalam melakukan perubahan kode saat melakukan maintenance karena website sudah terstruktur dengan metode MVC.
\end{abstract}

Kata kunci: Framework Codeigniter, Radio, Model View Controller (MVC).

Radio SSFM Semarang is one of the most popular radio in Semarang. This radio is one of the subsidiaries of Suara Merdeka Group. Radio SSFM Semarang needs to be developed in order to compete with other radio. One that needs to be developed is the SSFM radio website. This website was previously only used to stream and made with ordinary PHP that has not used the framework so it will be difficult to do maintenance. The research is redesigning to make significant changes to the website, so broadcasting can also be done with a modern, creative and innovative web-based system. The codeigniter framework and the Model View Controller (MVC) method are proposed to implement the Semarang SSFM website. The use of the codeigniter framework and the MVC method is proposed so that the website can be more easily to mantenance, fast, reliable and accessible. Websites that have been built have been tested with blackbox method and performance test with website load time measurement. The test results show that the use of MVC method can improve website load speed performance. With the results of the development of this website is expected to developers do not need much in making changes to the code when doing maintenance because the website is structured by MVC method.

Keywords: Framework Codeigniter, Radio, Model View Controller (MVC).

\section{Pendahuluan}

Radio SSFM yang beralamat Jl. Kawi Raya No.29 Wonotinggal Kota Semarang, Jawa Tengah, merupakan perusahaan yang dibawahi oleh Suara Merdeka Grup yang telah lama bergerak di bidang penyiaran radio, radio SSFM Semarang merupakan radio anak muda yang inspiring, dynamic dan entertaining [1]. Dengan dasar tersebut radio SSFM Semarang melakukan visi misinya, menjadi radio yang menginspirasi anak muda, menjadi radio dinamis dan dapat berubah mengikuti zaman, serta radio yang syarat menghibur. radio SSFM Semarang pernah memuncaki masa kejayaannya. Saat ini radio SSFM Semarang ingin mengulang kembali masa kejayaannya lagi setelah sekian lama vakum dalam dunia 
penyiaran, radio SSFM Semarang bakal dapat perubahan baru dalam menyampaikan penyiaran dengan sistem berbasis website yang modern, kreatif dan inovatif.

Melalui perkembangan teknologi informasi dan komunikasi, website dapat di akses secara cepat dan mudah. Website merupakan suatu kebutuhan bagi masyarakat modern saat ini, baik itu digunakan untuk melakukan transaksi, penyebaran informasi, maupun pencarian informasi [2]. Untuk mempercepat waktu pembuatan dan pengerjaan aplikasi berbasis web, telah banyak digunakan framework-framework web. Penggunaan framework web dalam sebuah proyek website dapat memberikan kemudahan bagi web developer dalam membangun sebuah proyek berbasis web.

Framework adalah sebuah perangkat lunak yang menyediakan fungsi generic sehingga dapat diubah oleh kode yang dibuat oleh user sehingga dapat menyediakan perangkat lunak untuk aplikasi tertentu, sedangkan codeigniter merupakan sebuah framework pemrograman yang menggunakan bahasa PHP [3]. Codeigniter dapat diperoleh secara gratis dan mudah digunakan untuk pemrograman selanjutnya dan dapat memodifikasi syntax yang telah ada.

MVC merupakan metode untuk membuat sebuah aplikasi dengan memisahkan bagian data Model, tampilan View, dan bagian proses Controller [4][5]. Dalam pembangunan suatu aplikasi akan menjadi lebih tertata rapi, sehingga dapat meningkatkan stabilitas dan efisien dalam proses pemeliharaan dan pengembangan aplikasi di kemudian hari, kelebihan yang terdapat pada MVC yaitu struktur file-nya tertata rapi dalam alur proses mudah sehingga pengembang tidak sulit lagi. Kelemahan MVC adanya peningkatan kompleksitas sehingga pada aplikasi kecil yang tidak loose coupling pada model yang menjadi blok penghalang dalam pola MVC[6][7].

Website radio SSFM Semarang saat ini hanya menggunakan website biasa yang hanya terdapat streaming lagu, website radio SSFM Semarang belum menggunakan Framework CodeIgniter dan tanpa terstruktur dengan metode MVC. Sehingga untuk pengembangan aplikasi website-nya sulit untuk menyampaikan informasi kepada pendengar setia radio SSFM Semarang.

Berdasarkan uraian di atas, penelitian ini difokuskan pada pembuatan website dan menganalisis kecepatan load website, diperlukannya membuat aplikasi website yang dapat memberikan informasi lebih tidak hanya streaming lagu, dengan implementasi menggunakan Framework CodeIgniter dan terstruktur dengan metode MVC pengembangan aplikasi ini dapat mengukur kecepatan proses load webiste radio SSFM Semarang ketika di akses. Selain itu aplikasi akan menjadi stabil dan mudah digunakan.

\section{Metode Penelitian}

\subsection{Pengumpulan Data}

Pada metode pengumpulan data ini penulis melakukan :

a. Studi pustaka, mengumpulkan data dari tulisan-tulisan ilmiah yang sesuai dengan membaca artikel internet, buku literatur dan informasi lainnya.

b. Observasi, guna mengamati dan mengumpulkan data dan informasi dalam membuat aplikasi ini. Guna membuat analisis aplikasi yang berjalan dan yang akan dibuat bersama pihak penyelia/staf IT di suara merdeka.

c. Wawancara, pada metode Wawancara ini, penulis melakukan wawancara dan pelaporan tahap per tahap dan direvisi langsung oleh pihak wakil penyelia yakni Pak Endro / Gawang selaku staf IT di Suara Merdeka guna hal yang dikembangkan / diperlukan dalam pembuatan sistem.

\subsection{Pengolahan Data}

Teknik analisis data dilakukan dengan cara terus menerus selama penelitian ini berlangsung, karena untuk menghindari adanya data yang tidak akurat maupun hilang ataupun rusak, data berdasarkan pada jenis data yang diperoleh di tempat penelitian ini berlangsung. Jenis data yang diperoleh adalah jenis data yang ada pada pengumpulan data di atas yang telah dijelaskan yaitu wawancara, observasi, dan studi pustaka.

\subsection{Model Pengembangan Sistem}

Metode yang digunakan dalam pengembangan sistem adalah Framework Codeiginiter dengan metode MVC. MVC dapat memisahkan pengembangan aplikasi berdasarkan komponen utama yang membangun sebuah aplikasi seperti manipulasi data, user interface dan bagian yang menjadi kontrol aplikasi [7]. Terdapat 3 jenis komponen dalam membangun suatu MVC, yaitu: 
a. Model, berhubungan langsung dengan database untuk memanipulasi data (insert, update, delete, search), menangani validasi dari bagian controller, namun tidak dapat berhubungan langsung.

b. View, merupakan bagian yang menangani presentation logic, pada suatu aplikasi web bagian ini biasanya berupa file template HTML, yang diatur oleh controller. View berfungsi untuk menerima dan mempresentasikan data kepada user. Bagian ini tidak dapat langsung berhubungan dengan model.

c. Controller, merupakan bagian yang dapat mengatur hubungan antara bagian Model dan bagian View, controller berfungsi untuk menerima request dan data dari user kemudian menentukan apa yang akan di proses oleh aplikasi.

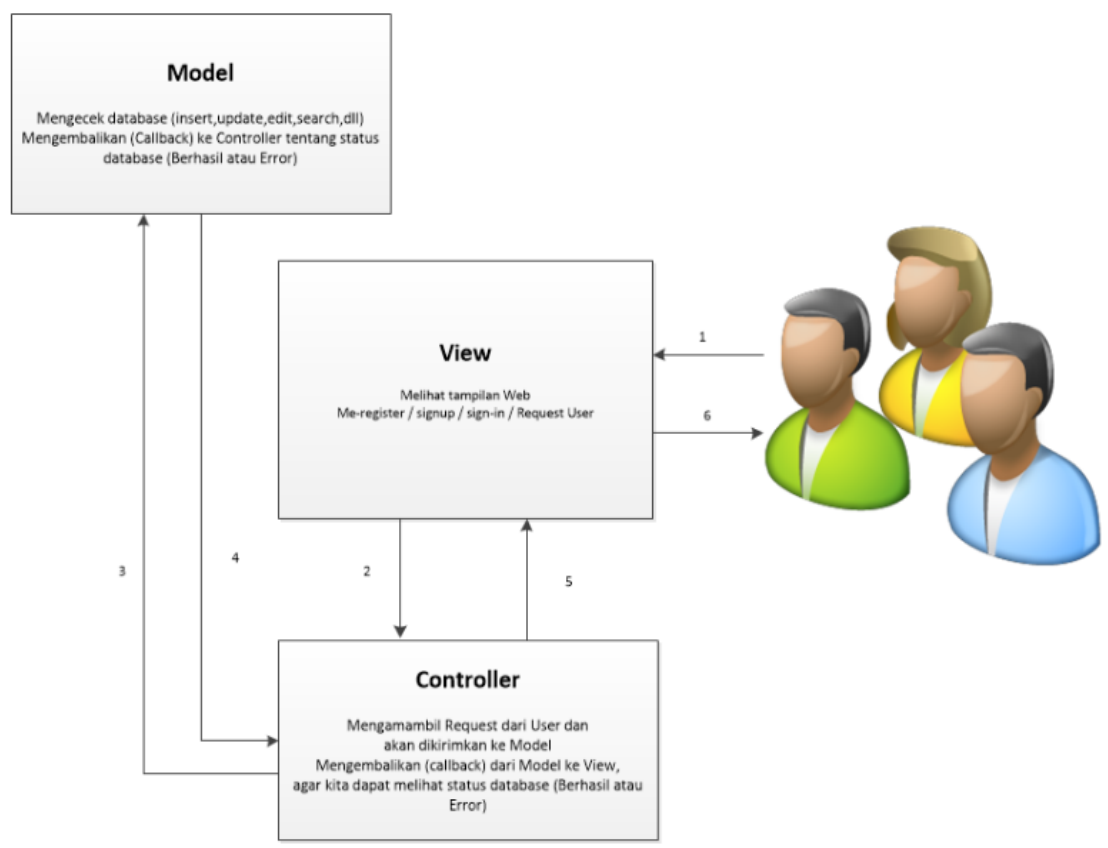

Gambar 1. Alur proses pembagian MVC.

Gambar 1 merupakan alur proses MVC. Ketika admin masuk terlebih dahulu harus login untuk dapat mengelola View manajemen admin tersendiri dan, kemudian masuk ke Model, berfungsi mengecek database dan mengembalikan database ketika berhasil atau gagal. Selanjutnya ke Controller, berfungsi mengambil atau mengelola request dari admin akan dikirimkan ke Model, kemudian Model ke View untuk menampilkan berhasil atau tidaknya.

\section{Hasil dan Pembahasan}

\subsection{Hasil Penelitian}

Proses ini, akan menampilkan hasil dari perancangan pada pembahasan sebelumnya. Hasil implementasi tersebut berupa tampilan user interface, screenshoot aplikasi. Berikut tampilan dari aplikasi tersebut:

\subsubsection{Tampilan website lama radio SSFM Semarang}

Gambar 2 merupakan tampilan website lama radio SSFM Semarang, dalam website lama tersebut tanpa Framework Codeigniter dan terstruktur model MVC, website lama hanya terdapat streaming lagu. 


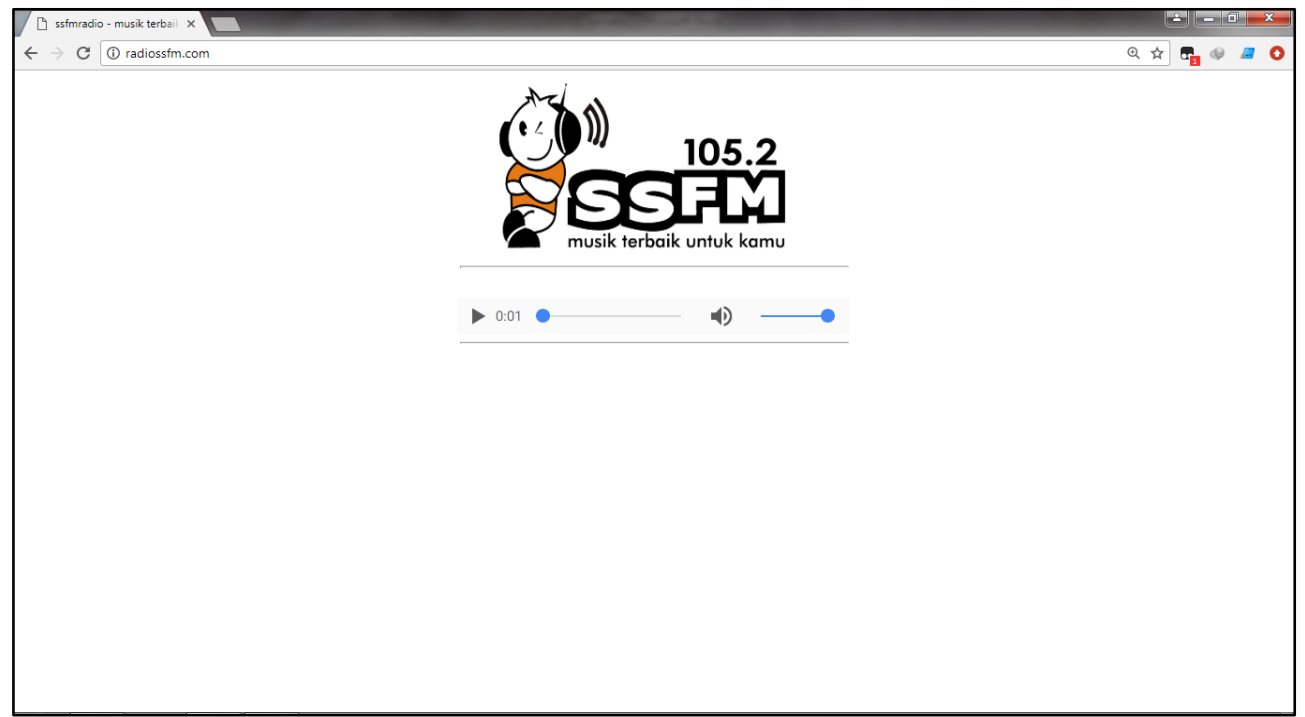

Gambar 2. Tampilan lama website Radio SSFM Semarang.

\subsubsection{Tampilan website baru radio SSFM Semarang}

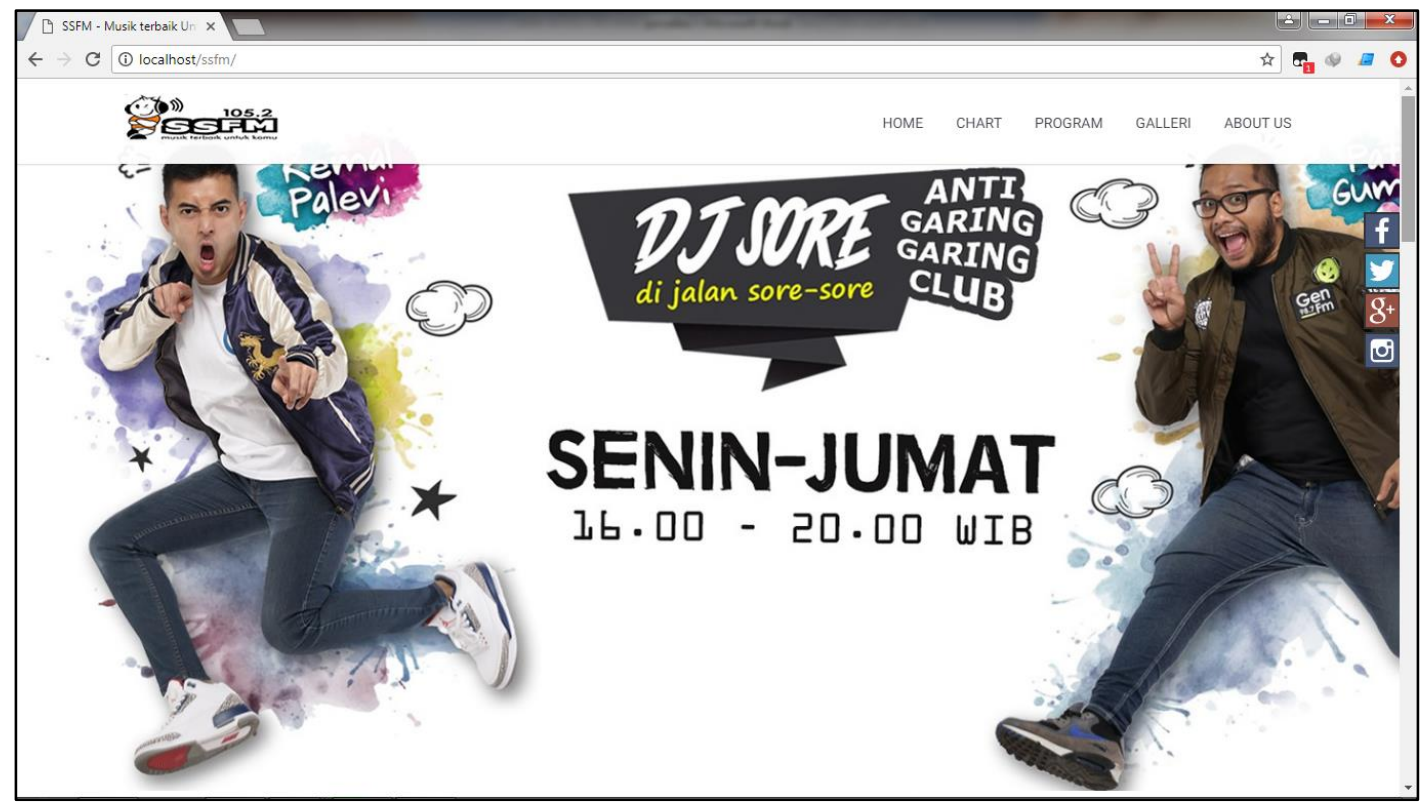

Gambar 3. Tampilan baru website Radio SSFM Semarang.

Gambar 3 merupakan tampilan website baru radio SSFM Semarang, dalam website baru tersebut menggunakan Framework Codeigniter dan terstruktur model MVC, dalam website baru interface-nya sudah modern banyak fitur, terdapat pilihan menu yaitu : Home, Chart, Galeri, About Us.

\subsection{Pengujian}

\subsubsection{Pengujian Black-Box Testing}

Dalam pengujian ini, dilakukan dengan pengimplementasian aplikasi radio SSFM Semarang. Pada proses pengujian ini rancangan prosesnya sudah sesuai apa tidak yang diharapkan oleh developer. Seandainya tidak akan diproses ulang agar dapat sesuai dan dapat di eksekusi ke pengguna agar bisa digunakan.

Tabel 1. Pengujian black-box.

\begin{tabular}{clll}
\hline No & Rancangan Proses & Hasil yang diharapkan & Hasil \\
\hline 1. & Mulai dengan membuka halaman web & Interfacenya rapi & Sesuai \\
\hline
\end{tabular}

Pengembangan Website Radio SSFM Semarang dengan Codeigniter Berbasis Model View Controller 


\begin{tabular}{|c|c|c|c|}
\hline 2. & Klik menu chart & Menampilkan daftar chart & Sesuai \\
\hline 3. & Klik menu program & Menampilkan program secara keseluruhan & Sesuai \\
\hline 4. & Klik menu news & Menampilkan berita & Sesuai \\
\hline 5. & Klik menu galleri & Menampilkan album dan foto & Sesuai \\
\hline 6. & Klik menu about us & Menampilkan boradcaster & Sesuai \\
\hline 7. & Live streaming & Masuk kehalaman streaming music & Sesuai \\
\hline 8. & Kemudian login ke halaman admin & Halaman login & Sesuai \\
\hline 9. & Isi username dan password lalu klik login & Masuk ke halaman utama admin & Sesuai \\
\hline 10. & Klik courosel & Masuk halaman data courosel & Sesuai \\
\hline 11. & $\begin{array}{l}\text { Mengisi nama corousel dan gambar lalu klik } \\
\text { simpan }\end{array}$ & Data tersimpan di database & Sesuai \\
\hline 12. & Klik hapus didata corousel & Data terhapus di database & Sesuai \\
\hline 13. & Klik chart & Masuk halaman data chart & Sesuai \\
\hline 14. & $\begin{array}{l}\text { Mengisi nama judul lagu, lyric, nama penyanyi } \\
\text { kategori dan gambar lalu klik simpan }\end{array}$ & Data tersimpan di database & Sesuai \\
\hline 15. & Klik hapus didata chart & Data terhapus di database & Sesuai \\
\hline 16. & Klik Our Program & Masuk halaman data Our Program & Sesuai \\
\hline 17. & $\begin{array}{l}\text { Mengisi nama program, deskripsi, kategori dan } \\
\text { gambar lalu klik simpan }\end{array}$ & Data tersimpan di database & Sesuai \\
\hline 18. & Klik hapus didata Our Program & Data terhapus di database & Sesuai \\
\hline 19. & Klik Berita & Masuk halaman data Berita & Sesuai \\
\hline 20. & $\begin{array}{l}\text { Mengisi judul berita, deskripsi, kategori dan } \\
\text { gambar lalu klik simpan }\end{array}$ & Data tersimpan di database & Sesuai \\
\hline 21. & Klik hapus didata Berita & Data terhapus di database & Sesuai \\
\hline 22. & Klik Galeri & Masuk halaman data Galeri & Sesuai \\
\hline 23. & $\begin{array}{l}\text { Mengisi nama foto, kategori dan gambar lalu } \\
\text { klik simpan }\end{array}$ & Data tersimpan di database & Sesuai \\
\hline 24. & Klik hapus didata galeri & Data terhapus di database & Sesuai \\
\hline 25. & Klik About Us & Masuk halaman data About Us & Sesuai \\
\hline 26. & $\begin{array}{l}\text { Mengisi nama broadcaster, jabatan dan gambar } \\
\text { lalu klik simpan }\end{array}$ & Data tersimpan di database & Sesuai \\
\hline 27. & Klik hapus didata about us & Data terhapus di database & Sesuai \\
\hline 28. & Klik logout & Keluar halaman utama admin & Sesuai \\
\hline
\end{tabular}

\subsubsection{Pengujian Time Request Web}

Dalam pengujian Time Request web terdapat dua perbedaan untuk mengecek kecepatan web antara dengan MVC, maupun tanpa MVC.

Tabel 2. Pengujian request time dengan cache kosong.

\begin{tabular}{|c|c|c|c|}
\hline No & Load proses dengan MVC & Load proses tanpa MVC & Selisih \\
\hline 1. & 5.83 seconds & 12.31 seconds & 6.48 seconds \\
\hline 2. & 5.08 seconds & 11.50 seconds & 6.02 seconds \\
\hline 3. & 6.45 seconds & 17.61 seconds & 11.16 seconds \\
\hline 4. & 6.34 seconds & 16.91 seconds & 10.37 seconds \\
\hline 5. & 2.40 seconds & 10.31 seconds & 7.91 seconds \\
\hline 6. & 2.80 seconds & 11.55 seconds & 8.75 seconds \\
\hline 7. & 3.40 seconds & 9.55 seconds & 6.15 seconds \\
\hline 8. & 3.56 seconds & 6.62 seconds & 3.06 seconds \\
\hline 9. & 4.17 seconds & 7.89 seconds & 3.72 seconds \\
\hline 10. & 4.31 seconds & 6.78 seconds & 2.47 seconds \\
\hline 11. & 4.39 seconds & 9.03 seconds & 4.64 seconds \\
\hline 12. & 4.80 seconds & 6.11 seconds & 1.31 seconds \\
\hline 13. & 4.92 seconds & 6.12 seconds & 1.20 seconds \\
\hline 14. & 5.12 seconds & 6.59 seconds & 1.47 seconds \\
\hline 15. & 5.18 seconds & 8.10 seconds & 2.92 seconds \\
\hline 16. & 7.11 seconds & 8.45 seconds & 1.34 seconds \\
\hline 17. & 6.88 seconds & 7.45 seconds & 0.57 seconds \\
\hline 18. & 5.79 seconds & 8.81 seconds & 3.02 seconds \\
\hline 19. & 4.41 seconds & 9.97 seconds & 5.56 seconds \\
\hline 20. & 5.51 seconds & 9.67 seconds & 4.16 seconds \\
\hline Jumlah & 98.45 seconds & 191.33 seconds & \\
\hline Selisih & 72.88 seconds & & \\
\hline Rata-rata & 7.24 seconds & & \\
\hline
\end{tabular}

Dalam 20 kali pengujian load time request web. dengan MVC dan tanpa MVC load prosesnya mempunyai hasil rata-rata 7.24 seconds dan selisih 72.88 seconds untuk pengujian dengan cache kosong. 
Tabel 3. Pengujian time request web dengan cache isi.

\begin{tabular}{llll}
\hline No & Load proses dengan MVC & Load proses tanpa MVC & Selisih \\
\hline 1. & 4.71 seconds & 9.65 seconds & 4.49 seconds \\
\hline 2. & 3.89 seconds & 10.79 seconds & 6.90 seconds \\
\hline 3. & 3.95 seconds & 8.84 seconds & 4.89 seconds \\
\hline 4. & 3.88 seconds & 9.66 seconds & 5.78 seconds \\
\hline 5. & 3.89 seconds & 9.65 seconds & 5.76 seconds \\
\hline 6. & 5.59 seconds & 11.55 seconds & 0.79 seconds \\
\hline 7. & 9.76 seconds & 10.55 seconds & 8.79 seconds \\
\hline 8. & 3.83 seconds & 12.62 seconds & 8.73 seconds \\
\hline 9. & 4.16 seconds & 12.89 seconds & 7.26 seconds \\
\hline 10. & 5.52 seconds & 12.78 seconds & 6.40 seconds \\
\hline 11. & 6.63 seconds & 13.03 seconds & 4.21 seconds \\
\hline 12. & 7.90 seconds & 13.11 seconds & 4.49 seconds \\
\hline 13. & 7.93 seconds & 12.12 seconds & 2.89 seconds \\
\hline 14. & 7.10 seconds & 11.59 seconds & 1.34 seconds \\
\hline 15. & 8.21 seconds & 11.10 seconds & 4.57 seconds \\
\hline 16. & 9.11 seconds & 10.45 seconds & 3.02 seconds \\
\hline 17. & 7.88 seconds & 12.45 seconds & 1.16 seconds \\
\hline 18. & 7.79 seconds & 11.81 seconds & \\
\hline 19. & 8.41 seconds & 11.97 seconds & \\
\hline 20. & 9.51 seconds & 10.67 seconds & \\
\hline Jumlah & 129.65 seconds & & \\
\hline Selisih & 97.63 seconds & & \\
\hline Rata-rata & 8.92 seconds & & \\
\hline
\end{tabular}

Dalam 20 kali pengujian load time request web dengan MVC dan tanpa MVC load prosesnya mempunyai hasil rata-rata 8.92 seconds dan selisih 97.63 seconds untuk pengujian dengan cache isi.

Dapat disimpulkan dengan melakukan pengujian load time request web yang dengan model MVC dan tanpa model MVC, terdapat dua pengujian dengan cache kosong dan cache ada, dengan hasil rata-rata cache kosong 7.24 seconds, selisih 72.88 seconds dan cache isi rata-rata 8.92 seconds, selisih 97.63 seconds. Dengan pengujian ini cache kosong load prosesnya cepat dibandingkan dengan cache isi.

\section{Kesimpulan}

Dari penelitian yang telah dilakukan dapat disimpulkan bahwa penggunaan metode MVC dan framework CodeIgniter dapat meningkatkan performa web radio SSFM Semarang. Hal ini dibuktikan dengan hasil uji coba time request. Selain itu juga ditambahkan berbagai fitur yang lebih banyak sehingga memberikan nilai lebih saat user mengakses website.

\section{Daftar Pustaka}

[1] J. S. Putra, "Kampanye PR Radio SSFM "Assik Ala SSFM"," Interaksi Online, vol. 1, no. 3, pp. 1-9, 2013.

[2] N. Ibrahim, "Pengembangan Aplikasi Semantic Web Untuk Membangun Web yang Lebih Cerdas," J. Inform., vol. 39, pp. 27-39, 2007.

[3] D. Rahmadiansyah, D. Irwan, D. Sekolah, and T. Teknik, "Implementasi Metode Model View Controller Menggunakan Framework Code Igniter dalam Pengembangan Aplikasi Manajemen Depo Petikemas pada Unit Usaha Belawan Logistics Center," Isbn 978-602-19837-0-6, no. Snastikom, pp. 1-11, 2012.

[4] D. Prabowo, "Website E-Commerce Menggunakan Model View Controller ( MVC ) Dengan Framework Codeigniter Studi Kasus : Toko Miniatur," Jurnal Ilmiah DASI, vol. 16, no. 1, pp. 23-29, 2015.

[5] D. A. R. Anggiani, R. Eko, "Perancangan Sistem Informasi Berbasis Website Subsistem Guru di Sekolah Pesantren Persatuan Islam 99 Rancabango,” Sist. Inf. Website, vol. 9, pp. 1-11, 2012.

[6] D. Ainur Rivai and B. Eka Purnama, "Pembangunan Sistem Informasi Pengolahan Data Nilai Siswa Berbasis Web Pada Sekolah Menengah Kejuruan (SMK) Miftahul Huda Ngadirojo," IJNS Indonesian J. Netw., vol. 2, no. 3, pp. 2302-5700, 2013.

[7] E. W. Hidayat, "Penerapan Pola Hierachical Model-View-Controller pada Rekayasa Sistem Berbasis Web Framework," J. Teknol. Technoscientia, vol. 3, no. 2, pp. 169-178, 2011. 